\title{
THIS
}

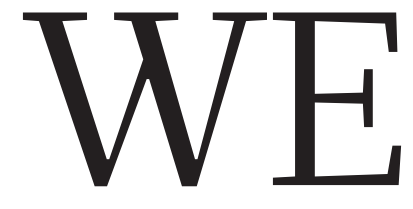

GARAGE FLOWERS Why the boom in DIY biology matters to scientists $\mathbf{p . 6 3 4}$
POSTDOcS Please release me, let me go to start my own lab p.635
BROUGHT TO BOOK Marine

census reveals its results $\mathbf{p . 6 3 8}$

\section{Stem-cell laws in China fall short}

\section{The Chinese government's regulations of stem-cell treatments are admirable in principle, but tougher enforcement measures are needed to protect patients.}

$\mathrm{C}$ hina does not want to be known as the Wild West of unproven medical technologies. Last year, the government took an important step when it announced regulations requiring, among other things, that anyone who offers stem-cell procedures should present clinical data supporting their efficacy, and secure approval from the health ministry (see Nature 459, 146; 2009).

Such regulations are sorely needed. A leading bioethicist in China last year estimated that more than 100 laboratories there offer stem-cell procedures, many of them unproven, although some clinics reportedly stopped offering the treatments after the regulations took effect. But the government needs to do more than simply announce rules; it needs to give companies clear instructions for complying with them.

The regulations have made little difference so far to Beike Biotechnology in Shenzhen, China's - and perhaps the world's - most prolific purveyor of stem-cell treatments. Beike develops therapies for disorders ranging from multiple sclerosis to lupus, based on adult and umbilical-cord stem cells. Its treatments, offered by more than 30 hospitals throughout China, have been injected into about 9,300 patients, who pay as much as US $\$ 26,000$ for the procedure. Roughly half have muscular dystrophy or spinal-cord injuries, but many experts say that stem-cell treatments for those conditions are not ready for clinical use.

Beike has not tested the efficacy of its treatments in formal clinical trials, says Alex Moffett, chief executive of Bangkok-based Beike Holdings and a spokesman for Beike Biotechnology, although he does say that some phase I safety trials are taking place. The company offers numerous testimonials on its website as evidence that its treatments work. But some media accounts report scepticism, and the mother of one Beike patient complained directly to Nature that her son's condition did not improve at all.

Moffett says that he believes in the need for evidence based on clinical trials. As the company plans an expansion into Malaysia, the Philippines and Thailand, he says, it will complete clinical trials of every treatment's safety and efficacy, at no cost to patients, before offering the procedures commercially. He says that Beike "probably should have" taken the same approach in China.

Yet the company has passed muster with the government, says Moffett. Officials have visited Beike's facilities without closing them down, which he interprets as tacit approval for the treatments. He says he knows of no application steps for formal approval from the health ministry - and requested that Nature forward him any information about such procedures.

The problem, it seems, is that the regulations do not include enough details for implementation and enforcement. The health ministry is now considering proposed guidelines, created by a group of scientists and ethicists, that set out clear criteria for preclinical and clinical studies, and clinical applications. One of the committee members said that the guidelines call for an approval process that is easily accessible, includes an ethical review and is based on solid scientific data.

The committee member says that the government will decide "soon" whether and how to implement the guidelines. (A Chinese academic who has been following the issue says that implementation has been held up by disagreements between different government agencies.)

Soon cannot be soon enough. The guidelines need to be approved and put in place as fast as possible, and enforced swiftly and effectively. The longer that unproven therapies stay on the market, the greater is the risk that a history of use can be framed as evidence of safety and efficacy.

Since an investigation of China's food and drug agency a few years ago found it to be rife with corruption (see Nature 446, 598-599; 2007 and Nature Med. 13, 889; 2007), the government has worked hard to put together a system that balances drug-company profit, the requirements of drug innovation, and patients' health and welfare. Those efforts offer a model for regulation of stem-cell therapies. Anything less than a clear, detailed set of rules is a disservice to scientists who are working hard to understand stem cells and their clinical promise, to companies that are taking big financial risks and doing proper clinical trials, and most of all to patients.

\section{Transgenic harvest} African nations are laying foundations to extend
the use of GM technology on the continent.

$\mathrm{T}$ he use of genetically modified (GM) crops for food divides opinion, especially when it comes to Africa. Sharp views on the technology in the developed world, honed by more than a decade of arguments in Europe and elsewhere, are too easily projected onto Africa, with the continent portrayed as a passive participant in the global melodrama over GM food. So it is heartening to see a group of 19 African nations working to develop policies that should make it clear to all sides in the debate that Africa can make up its own mind.

After more than nine years, talks between member states of the Common Market for Eastern and Southern Africa (COMESA) have produced a draft policy on GM technology, which was sent for national consultation last month. COMESA is a trade bloc, and its proposals aim to develop research and trade in GM crops. But they also state that decisions should be based on sound science and evidence.

Under the proposals, a nation that wants to grow a GM crop commercially would inform COMESA, which would then carry out a science-based risk assessment - COMESA seems to have sufficient access to scientific expertise to fulfil this role. The body would judge 